The University of Maine

DigitalCommons@UMaine

Publications

Senator George J. Mitchell Center for Sustainability

Solutions

$12-2015$

\title{
Public Preferences for Investments in Renewable Energy Production and Energy Efficiency
}

Caroline L. Noblet

University of Maine, caroline.noblet@maine.edu

Mario F. Teisl

University of Maine - Main, teisl@maine.edu

Keith S. Evans

University of Maine, keith.evans@maine.edu

Mark W.Anderson

University of Maine

Shannon McCoy

University of Maine, shannon.mccoy@maine.edu

See next page for additional authors

Follow this and additional works at: https://digitalcommons.library.umaine.edu/ mitchellcenter_pubs

Part of the Environmental Studies Commons, and the Social Influence and Political Communication Commons

\section{Repository Citation}

Noblet, Caroline L.; Teisl, Mario F.; Evans, Keith S.; Anderson, Mark W.; McCoy, Shannon; and Cervone, Edmund, "Public Preferences for Investments in Renewable Energy Production and Energy Efficiency" (2015). Publications. 101.

https://digitalcommons.library.umaine.edu/mitchellcenter_pubs/101

This Article is brought to you for free and open access by DigitalCommons@UMaine. It has been accepted for inclusion in Publications by an authorized administrator of DigitalCommons@UMaine. For more information, please contact um.library.technical.services@maine.edu. 
Authors

Caroline L. Noblet, Mario F. Teisl, Keith S. Evans, Mark W. Anderson, Shannon McCoy, and Edmund Cervone 


\section{Public preferences for investments in renewable energy production and energy efficiency}

Caroline L. Noblet ${ }^{\mathrm{a},}$, Mario F. Teisl ${ }^{\mathrm{a}}$, Keith Evans ${ }^{\mathrm{b}}$, Mark W. Anderson ${ }^{\mathrm{a}}$, Shannon McCoy ${ }^{\mathrm{c}}$, Edmund Cervone ${ }^{\mathrm{d}}$

a School of Economics, University of Maine, United States

b School of Economics and School of Marine Sciences, University of Maine, United States

c Department of Psychology, University of Maine, United States

d Educate Maine, United States

* Corresponding author

E-mail addresses: caroline.noblet@maine.edu (C.L. Noblet), teisl@maine.edu (M.F. Teisl), keith.evans@maine.edu (K. Evans), marka@maine.edu (M.W. Anderson),

Shannon.mccoy@maine.edu (S. McCoy), ed@educatemaine.org (E. Cervone). 


\begin{abstract}
In this paper we investigate the choices citizens make when asked to express willingness to support a proposed energy policy and are then compelled to allocate the program funds to either renewable energy or energy efficiency. In a survey study based on a random sample of residents of the state of Maine, USA, we find that citizens have preferences for specific types of renewable energy but these preferences do not yield significantly different allocation of investment funds between renewable energy and energy efficiency. We find that preferences are generally consistent regardless of presentation of options (i.e. limited ordering effects). Our results also indicate that personal characteristics that are understudied in the energy literature, including promotion/prevention focus and social/fiscal leanings, influence both willingness to support energy policies and also their allocation of fund choices, but in different ways. This suggests the importance of including multiple options in energy policy proposals, and that targeted messages regarding the components of such policies is key for optimal communication.
\end{abstract}

Keywords:

Energy efficiency, Renewable energy, Allocation, Promotion and prevention focus 


\section{Introduction}

For over forty years energy policy research has addressed the question of potential alternatives to fossil fuels currently used to energize global economies (Landsberg, 1974). Yet fossil fuels continue to dominate among all primary energy resources despite expressed support by citizens worldwide for alternative energy sources, e.g. in the United States, (Farhar, 1994; Roe et al., 2001; Greenberg, 2009) Italy (Cicia et al., 2012), Turkey (Ertör-Akyazı et al., 2012), and Portugal (Ribeiro et al., 2014). This persistence of conventional energy reliance despite public support for alternatives reflects both the challenges inherent in shifting from one primary energy source to another (Smil, 2003) but also the potential trade-offs associated with energy demand reduction. What is missing in many of the studies of energy policy is recognition that the public is not just concerned with energy supply issues but also with demand, where both are 'affected as much by individual choice, preference and behavior, as by technical performance' (US Department of Energy, as quoted by Sovacool (2014)).

Alternative sources of primary energy supply exhibit a mix of costs and benefits such that none is unambiguously optimal from all perspectives. Alternatives to fossil and nuclear based power are renewable (products of the hydrologic cycle or of net primary productivity of photosynthesis), reduce reliance on imported hydrocarbons (improving balance of trade metrics and national security), and may lower global climate change effects. Alternatives may also create locally undesirable land uses (LULUs), threaten surface or ground water quality, and exhibit lower power densities than conventional primary energy sources (Smil, 2003). Public perceptions of alternative energy policy in the US and elsewhere often reflect an understanding of the tradeoffs among primary energy sources. 
conventional and alternative primary energy supplies, but also efficiency in energy use and changes in lifestyle (Deitz et al., 2013). Of the 97 quads of estimated primary energy supply for the US economy in 2013 , only about $40 \%$ delivered energy services while the remainder was 'rejected energy' reflecting inefficiencies in the conversions from primary to secondary forms, losses in distribution, and inefficiencies in use of secondary energy in end-use technologies (Lawrence Livermore National Laboratory, 2014). Moreover, the energy intensity of global economies (measured as units of energy per dollar of GDP) has been declining since the middle of the 1970s in most parts of the world reflecting the importance of investments in energy efficiency (BP, 2013, p. 18). Thus, when policy makers and the public consider energy futures there must be an understanding that the future will include a mix of conventional energy sources, development and expansion of alternatives because of their renewability or other 'green' characteristics, and investments in energy efficiency.

This paper identifies factors contributing to consumers' 'preferred mix' by evaluating tradeoffs between investments in different types of renewable energy and energy efficiency, and importantly identifying different factors which may influence these distinct decisions. Consistent with Sovacool (2014) call for researchers to include twelve under-represented components in future energy work, we incorporate both the role of an individual's political perspectives and social psychology metrics in evaluating consumer preferences. The objective of this study is to measure public preferences for investment in alternative sources of renewable energy supply and in energy efficiency that would affect energy demand. Importantly, we extend prior work by examining facets of public choice: support for policy, preferences for allocation of policy dollars and the economic and personal factors that explain these distinct energy choices. The design of this research was adopted in recognition that energy futures will include multiple interventions to affect both supply and demand, and that these futures are highly dependent upon public preferences and support. Consistent with Menegaki (2008) definitions of valuation and evaluation, we offer insight into consumer evaluation of renewable energy sources and energy 
efficiency using data collected from residents of Maine, USA. Maine, a state located in the northeastern corner of the United States, is an apt study site for testing public preferences regarding energy efficiency and renewable energy in part because of strong investments in both of these facets of an energy portfolio.

2. Previous research and current hypotheses

Paul Stern recently reminded the research community that when it comes to energy issues 'We need all hands on deck' (Stern, 2014). He urged multi-and interdisciplinary teams to focus their efforts on the pressing energy issue. Similarly, Sovacool (2014) and Sovacool et al. (2015) noted a disturbing trend of undervaluation of the influence of social dimensions on energy. We respond to these calls with inclusion of factors and techniques employed across both the fields of economics and psychology in the current work.

\subsection{Energy choices}

The growing literature on individual-level energy decision making offered fertile fields for the development of this current work. Willingness to fund changes in energy policy may be viewed as a pro-environmental behavior intention (Ajzen, 1991; Stern, 1992). While pro-environmental behavior has often been described as a single behavior, rather than distinct sets, this assumes that different types of environmental behavior are determined by similar factors (von Borgstede et al., 2013). We operate under the assumptions that different antecedents affect different types of environmental behaviors and recognize the gap between stated behavioral intentions and behavior. The literature repeatedly demonstrates a willingness-to-pay (WTP) for green electricity, however the low participation rate in green power programs indicates an intention to behavior gap that must be addressed by researchers (Tabi et al., 2014; Borchers et al., 2007). 
Research methods are one potential explanation for the incongruence between research findings in the energy literature and consumer behavior in the market. When studying consumer preferences for energy options, researchers may provide participants vague options to support such as 'renewable energy' that are generic and lack specification (von Borgstede et al., 2013). These presentations are thus more distant to the consumer and more positively evaluated than concrete renewable energy options may be in the marketplace (von Borgstede et al., 2013). Borchers et al. (2007) investigated the impact of asking consumers to evaluate 'generic' green energy in relation to specific green energy types and found that consumers did not perceive all green energy sources as equivalent. Rather people had source-specific demand attributes that go undisclosed when renewable energy is packed as a generic unit. Other work has focused on providing specific energy types for consumers to select from in order to investigate whether consumers reveal demand for specific green energy sources (Grösche and Schröder, 2011; Roe et al., 2001). Findings indicate that consumers do not perceive green energy sources as equivalent (Tabi et al., 2014; Kontogianni et al., 2013; Sardianou and Genoudi, 2013; Grösche and Schröder, 2011; Borchers et al., 2007; Roe et al., 2001) and may have some confusion over the generic term 'renewable energy' (Zarnikau, 2003). The above literature leads us to:

H1. : We hypothesize that consumers will reveal different levels of willingness to support an energy policy scenario dependent upon the type of renewable energy and order of options presented within the scenario.

Importantly, participants in polls and studies are often not asked to select or balance their priorities (i.e. engage in cardinal ranking), rather they are merely called upon to indicate support or not (Manley et al., 2013). For example, Pew Research Center for the People and the Press (2010) polls, indicate that $87 \%$ of respondents favored renewable energy legislation, while $78 \%$ supported higher efficiency standards. These numbers suggest that citizens may support seemingly competing goals given limited financial and other resources to support energy 
initiatives. In an effort to address this prioritization gap, von Borgstede et al. (2013) find that the top two energy-related policies supported by Swedish citizens were increased financial investment in renewable energy and energy-saving measures. In asking consumers to prioritize, Zarnikau (2003) found that energy efficiency became a priority energy option at the expense of renewable energy support. Further, a key feature of the rational choice model is that preferences or ranking are consistent regardless of the order in which alternatives are presented and the label they carry. Economic theory indicates that these contexts should not affect an individuals' decision. However, studies have repeatedly shown the potential for ordering and labeling effects, in part attributable to status quo bias (Samuelson and Zeckhauser, 1988; Painuly, 2001). Taken collectively, these findings indicate that researchers must be cautious in how material is presented to participants to ensure accurate results.

\subsection{Role of economic and personality variables in decision-making}

Models aimed at revealing factors influencing WTP for energy alternatives have often not accounted for a high proportion of variance (see Bamberg (2003) for a review; Hansla et al., 2008; Scarpa and Willis, 2010). We review the factors frequently included in energy choice models (i.e. socio-demographics, antecedents to environmental choice), and then draw upon both social psychology and political leanings in developing our model for energy choices.

\subsubsection{Socio-demographic}

A number of key factors have been identified in explaining household decisions to support green energy (i.e. policy support or willingness-to-pay). One's behavioral control, or the degree to which one perceives they can perform the behavior, may depend on the anticipated overall cost burden of the program to the household (Zarnikau, 2003). This set of factors typically incorporates household size (Grösche and Schröder, 2011; Gerpott and Mahmudova, 2010), 
current electricity bill (Zarnikau, 2003; Sardianou and Genoudi, 2013), location of the household (Grösche and Schröder, 2011), income (Ek, 2005; Borchers et al., 2007; Grösche and Schröder, 2011; Sardinaou and Genoudi, 2013) and the cost of the program presented to the consumer (Hansla et al., 2008; Borchers et al., 2007). Higher levels of education have been noted for consumers who support or adopt green energy (Tabi et al., 2014; Sardianou and Genoudi, 2013; Ek, 2005; Zarnikau, 2003). Gender effects have been mixed, where some studies find no effect (Sardianou and Genoudi, 2013), others find that females prioritize the environment over security and economic goals (Manley et al., 2013), and still others find males are more willing to pay for renewable energy, but there is no gender effect in payment for energy efficiency programs (Zarnikau, 2003). The impact of age has also been investigated and found to impact energy choices (Sardianou and Genoudi, 2013; Zarnikau, 2003) although results are inconsistent showing both an increase in support and decrease in WTP as age increases (Borchers et al., 2007; Zarnikau, 2003).

In addition to demographic factors individuals expressing environmental concern are often found to indicate preference for green alternatives (Borchers et al., 2007; Balderjahn, 1988; Roberts and Bacon, 1997) including in the energy realm (Hartmann et al., 2005; Sapci and Considine, 2014). Evidence suggests that the relative importance of psychological variables, such as environmental attitudes and concern, is domain specific (see Stern (2011) for a review). Hansla et al. (2008) noted a lack of specificity between WTP for green electricity and the more general attitude and environmental concern metrics captured in their study; they hypothesized that this lack of specificity may in part contribute to the low explanatory power of their models. This has led other researchers to include metrics specific to the environmental issue of concern with energy, climate change (e.g. Spence et al., 2010; Kontogianni et al., 2013). For example Kontogianni and colleagues included a climate change risk question which significantly explained preferences for onshore (negative effect) and offshore (positive effect) wind selection. Importantly, this work demonstrates both the importance of renewable choice specificity (off- 
shore vs. onshore) as previously noted, but also the need to capture domain specific psychological metrics in models.

\subsubsection{Promotion and prevention focus and political leaning}

An individual's values, personality characteristics and the context in which they make decisions have been found to contribute to willingness-to-pay decisions for eco-labeled electricity (Hansla, 2011) and other pro-environmental behaviors (Stern, 1992; Hansla et al., 2008b; Hernandez et al., 2010). This previous work yields the opportunity to further investigate the role of an individual's personal characteristics and the interaction with context as a potential explanatory factor in energy decisions. An individual's evaluation of (Aaker and Lee, 2001) and choice among alternatives (Kirmani and Zhu, 2007) is influenced by whether they are promotion or prevention focused, known as regulatory focus theory. Individuals with a predominant promotion focus are concerned with advancement, growth and accomplishment including an openness to change (Crowe and Higgins, 1997; Liberman et al., 1999). In contrast, preventionfocused individuals are concerned with protection, safety and responsibility, to be 'prudent and precautionary' (Crowe and Higgins, 1997 p. 130; Higgins, 2000, 2002; Pham and Chang, 2010). Consumers may actively seek information, or adopt strategies that fit with their focus including engaging in selective attention; Wang and Lee (2006) find that individuals use this focus as a heuristic when allocating scarce cognitive resources. Importantly, prevention focused consumers may feel a duty towards a green lifestyle due to their focus on responsibilities (Lucas and Molden, 2011); promotion focused individuals may not feel this same sense of duty (Miniero et al., 2014). Indeed, a promotion focus facilitates increased consumption whereas prevention focus reduces consumption (Förster, 2003). Further, recent studies have found that participants placed more weight on product features that fit their regulatory focus which has implications for energy choices (Wang and Lee, 2006). If energy efficiency is seen as 'preventative' in nature, whereas renewable energy is marketed as 'advancement' these two energy measures will be 
attractive to individuals of different regulatory focus. We may also consider the role of risk evaluation by individuals with different regulatory focus. Given the prevention focus on avoiding negative outcomes uncertainty is to be avoided, where promotion focused individuals display more risky approaches (Boldero and Higgins, 2011; Werth and Förster, 2007; Crowe and Higgins, 1997). To consumers, renewable energy may be perceived as more 'risky' given that the long-term benefits/ costs are unknown, whereas energy efficiency is long established with more known risk/benefits.

In considering the relationship between energy choice and regulatory focus, we must also contemplate the potential role of political leaning. McGregor et al. (2001) notes that conservatism is often associated with uncertainty avoidance and indeed Jost et al. (2003) hypothesized that regulatory focus may predict political preferences to the extent that political conservatism is motivated by desire for security/stability. Regulatory theory predicts that a prevention focus would yield greater support for government policies ensuring public safety or those designed to protect/ maintain a status quo, where a promotion focus would generate greater support for policies and interventions related to opportunities for growth. Positive relationships have been noted between promotion focus and votes for 'economic reform' but a negative association between prevention focus and economic reform (Boldero and Higgins, 2011). This has important implications for the role of political leaning in energy decisions given that conservative 'anti-environment' orientation may be traced to political leaders who set economic wellbeing and environmental protection as mutually exclusive goals (Dunlap and McCrights, 2008). Additionally, research has shown a significant relationship between party affiliation and belief in global climate change (Dunlap and McCrights, 2008) and positive relationships between liberalism and protection of the environment (Lucas and Molden, 2011). Thus, while Pew Research Center for the People \& the Press (2010) polls note that Democrats (a center left party) favor alternative energy development more than Republicans (a center right party) it remains an open question whether the same, or reverse pattern, holds for energy 
efficiency. The extensive literature on economic and personality characteristics yields our second hypothesis.

H2. : We present participants with two related energy decisions: first, garnering their willingness to support an energy investment program and second, allocating the investment program funds between renewable energy and energy efficiency. We hypothesize that the economic and personal characteristics which influence these decisions will differ dependent upon whether the individual faces a 'willingness to support' decision or an 'allocation of funds' decision. Economic variables (income, current household electricity bill, etc.) and political variables (fiscally conservative) traditionally influence willingness to support decisions, however their effect on the allocation decision remains an open question. Further, we hypothesize that individuals with a promotion (prevention) focus will indicate more (less) willingness to support and choose to allocate more (less) of the investment resources to renewable energy. We also anticipate that specific issue-focused belief metrics (i.e. beliefs about relationships between renewable energy and energy efficiency as well as climate change) will be significant in energy policy decisions.

3. Methods

\subsection{Sampling and data collection}

The current study uses data from a state-wide survey of randomly selected residents of Maine, USA, 18 years or older. We set our work in the state of Maine in the northeastern corner of the United States. We believe Maine is an apt testing ground for public preferences regarding renewable energy and energy efficiency given Maine's historic and current use of renewable energy, where over half of Maine's 2013 net electricity generation came from renewable energy resources (Energy Information Administration, 2014). Additionally, Maine has aggressive 
renewable energy portfolio goals and strong investments in energy efficiency (Database of State Incentives for Renewables and Efficiency, 2014). Further, as a predominantly rural state with a few growing metropolitan areas, Maine faces both substantially changing demographics including an influx of retirees and individuals from other states, and an outmigration of Maineraised young people. Thus, we are able to capture individuals from varied backgrounds and current lifestyles.

The survey was administered in a two-round modified Dillman method between May and September of 2013 (Dillman et al., 2009). The initial invitation to participate and survey instrument were accompanied by one-dollar, a form of incentive proven to improve response rates (Teisl et al., 2006). Subsequent rounds contained a copy of the survey and a reminder letter. In key demographic characteristics our respondents are similar to the Maine population but are older, more likely to be male and have a higher income (Table 1.)

\subsection{Policy scenario and variables}

There were twelve versions of the questionnaire which allowed for multiple experiments within the design. The present analysis relies on one version of the survey with a response rate of $33 \%$. Section 1 of the survey gathered information on a respondents background knowledge of, and preferences for, energy production in Maine. In section two, respondents participated in the experiment which is the focus of this analysis. First, respondents were asked about the amount of their monthly electricity bill in order to make energy costs salient. Respondents were then presented with the information and scenario in Fig. 1.

The amount requested for investment (per month fee) varied across participants ranging from a low of $\$ 1$ to a high of $\$ 15$. The renewable energy option included within the policy scenario also differed across participants as each participant was asked to consider investing in one of the 
following energy supply types: hydroelectric energy, land-based wind, deepwater offshore wind, or tidal energy. As depicted in Fig. 1, energy efficiency was always provided as an option within the policy, and was always listed after the renewable energy type in the policy description. While this mix of renewable energies presented is generally consistent with other studies in presenting wind and hydropower (Sardinou and Genoudi, 2013; Kontogianni et al., 2013), we do not include solar, biomass or geothermal which are often included in renewable energy studies (Sardinou and Genoudi, 2013; Roe et al., 2001). We focus on the four energy generation potentials being used (land-based wind, hydroelectric) or being developed (both deepwater offshore wind and tidal energy have pilot generation projects $)^{1}$ in Maine. Consistent with our literature review we provide the specific types of renewable energy that may be financed and a specific payment vehicle to enable testing of differences across the energy types and to reduce scenario rejection. We recognize that consumer preferences may differ across payment vehicles associated with policy options (for example, Sardinou and Genoudi (2013) found participants preferred tax deductions as a means of introducing renewable energy into homes), however for this experiment payment via monthly electric bill was the only scenario presented (Zarnikau, 2003). In the second question of the scenario we alternated the placement of energy efficiency and the renewable energy, such that half of respondents within a renewable energy type saw the scenario as presented in Fig. 1 and half saw the renewable energy option in the first column and energy efficiency in the second column. This design allows us to test for potential ordering effects.

Four hundred and seventy four individuals participated in this experiment, however 77 were removed from further analysis due to incomplete responses (i.e. they did not answer the support question). Section three of the survey gathered information about respondents' opinions on a number of human-environment interaction issues (including global climate change perceptions), regulatory focus (promotion or prevention), and political leanings. Section four contained detailed socio-demographic questions. 


\subsection{Statistical methods}

We used several different approaches to examine our data and test our hypotheses. We used analysis of variance and cross-tab analysis to determine whether supporters of the proposed scenario were significantly different than those who did not support the proposed program and further to test whether reported support for the proposed program differed across renewable energy presented in the scenario. We employed further inferential statistics to determine if allocation of the policy funds differed dependent upon either the type of renewable energy presented or ordering effects (H1). We estimated a Heckman selection model with an ordered probit in Stata 14 (StataCorp, 2015) to examine factors impacting both the willingness to support the energy policy and the allocation of funds decision $(\mathrm{H} 2)$.

\subsection{Limitations}

We recognize that our work has limitations and acknowledge them here in the hopes that future contributors may be better able to address them. As with all stated preference data, our data collection method has implications for our conclusions. Grösche and Schröder (2011) note that in stated choice, participants have limited incentives to reveal preferences truthfully because there are no direct consequences to the participant (financial or otherwise). Further, Ek (2005) notes embedding effects, where respondents include other elements in the decision than those intended by researcher when stating their preference. For example, the time horizon associated with implementation of our policy scenario was not given to respondents, but may have impacted their decision. We do not have knowledge of citizens' perceptions of the time needed to implement the options presented in the energy policy scenario, and whether this time would vary based on renewable energy type or energy efficiency efforts pursued. We also acknowledge that some participants may have desired additional information about the levelized cost of these 
energy options across time. Further, we recognize that while we offered specificity in the renewable energy choices presented, we did not offer the same level of detail with energy efficiency, rather we offered limited information about the type of investments covered by our generic 'energy efficiency'. Respondents' choices may have been impacted by their expected receipt of proposed funds. At present, Efficiency Maine (Maine's quasi-governmental agency dedicated to energy efficiency efforts) programs often support lower-income households and/or energy efficiency in businesses. We cannot know if an individual in our study has a personal motivation for favoring the energy efficiency option in anticipation of reducing their own energy costs due to the focus of existing state programs (Zarnikau, 2003).

This work is limited by the study site. Maine, USA is a unique state and therefore the results best fit Maine. One example is Maine's highly natural resource dependent economy which may at times be perceived as conflicting with certain renewable energy options (e.g., commercial fishing and tidal energy). Thus, our data provides interesting insights into this energy choice dilemma, but our sample may limit the external validity of our results.

4. Results and discussion

\subsection{Willingness to support proposed energy policy}

Fifty-two percent, 207 respondents agreed to support the proposed energy policy (Fig. 1, question 6), where this support differed across energy type $(t(395)=4.0, p=.008)$ and amount of fee $(t(395)=5.75, p<.0001)$ (Table 2; Fig. 2). While previous studies and polls have found higher rates of participation in willingness-to-pay for renewable energy or energy efficiency programs (i.e. Kontogianni et al. (2013) found a 77\% willingness-to-pay for renewable energy; Pew Research Center for the People \& the Press (2010) polls found 78\% support higher energy efficiency standards), the split in our data (52\% support rate) provides sufficient variation to 
further examine factors impacting support or rejection of the proposed policy.

Consistent with our second hypotheses, we find the socio-demographic and personal characteristics of policy supporters and non-supporters are significantly different (Table 3.) We include variables aimed at controlling for respondents differences in demographic profiles (age, gender, education level, presence of children in the household, household size), including financial constraints such as income and current monthly electricity bill. We also include a variable which captures the numbers of years a participant has lived in Maine. To test our hypothesis regarding the role of political leanings, promotion/prevention focus and domain specific attitudes we capture additional metrics. To investigate the role of domain specific attitudes, we include responses on Likert scale ( $1=$ strongly disagree, $7=$ strongly agree $)$ to three statements: (1) climate change is happening and has anthropocentric causes (composite variable); (2) renewable energy is taking the focus off of Maine's need to improve energy efficiency and (3) renewable energy is taking the focus off of Maine's need to reduce energy consumption'. Promotion/Prevention (regulatory) focus was captured through inclusion of a composite variable of three promotion oriented questions $(\alpha=.67)$ using the above Likert scales, where higher agreement indicated more promotion focus and three prevention oriented questions $(\alpha=.60)$. Participants provided their political leanings by responding to a scale of $1=$ liberal and 7=conservative for both social and fiscal leanings.

\subsection{Allocation of program funds}

We are interested in determining whether Maine citizens have undisclosed preferences for energy efficiency or renewable energy investments, and how these choices can be impacted by something as simple as order of presentation. In analyzing responses to the allocation scenario (Fig. 1, question 7) we find that some of our participants may view energy efficiency and renewable energy as complementary efforts; $37 \%$ of respondents allocated $50 \%$ of their funds to 
energy efficiency and 50\% to renewable energy. However, a majority of our participants indicated a preference for energy efficiency investments where $76 \%$ of respondents allocated $50 \%$ or more of funds to energy efficiency. While $6 \%$ of participants allocated zero funds to energy efficiency and $13 \%$ allocated all funds to energy efficiency, the mean allocation of funds was not different across the various energy types participants considered $(F(3)=0.61, p=0.61)$ nor was the distribution $(18.14, p=0.95)$; regardless of renewable energy type considered participants allocated $56 \%$ of funds on average to energy efficiency.

We find limited order effects in allocation of program funds. When individuals are presented with the renewable energy 'land-based wind' in the first (second) column under the allocation section, they allocate $57.3 \%(65.8 \%)$ of funds to energy efficiency $(t(47)=0.92, p=0.36)$. Similar results hold for 'deepwater offshore wind' where participants allocated 50\% (60.7\%) of funds to energy efficiency when deepwater offshore wind was viewed first (second) $(t(47)=1.24, p=.22$ ). Participants viewing tidal energy $(t(55)=0.72, p=0.47)$ allocated $51.8 \%(56.4 \%)$ to energy efficiency when viewed first (second). We do find evidence of order effect when participants considered hydroelectric energy. Participants who were presented with the renewable energy option of 'Hydroelectric' first allocated significantly less funds to energy efficiency (46.3\%) than when energy efficiency was viewed first and Hydroelectric second (62.4\% to energy efficiency) $(t(47)=1.96, p=0.05)$. In explaining this result, we can consider that hydroelectric energy is already a primary component of Maine's energy portfolio. While the other renewable energy sources listed can be considered 'new' to Maine, hydroelectric may be on more equal footing with energy efficiency as both have been used long-term in Maine.

\subsection{Regression analysis of willingness to support and allocation of funds decisions}

We hypothesized that different antecedents may impact the willingness to support decision (Fig. 1, question 6) than the allocation decision (Fig. 1, question 7). To further examine our 
preliminary findings we employ a Heckman selection model with an ordered probit ${ }^{2}$. The willingness to support dependent variable is coded as 1 if the participant indicated 'yes' 0 if no. Independent variables in the regressions include the socio-demographic and personality variables included in Table 3 . We add indicator ${ }^{3}(0 / 1)$ variables to denote the renewable energy type presented (deepwater offshore wind, hydroelectric and tidal; land-based wind is the omitted, baseline category) and the amount of the fee associated with the policy. Given the use of the probit model, we cannot interpret the marginal effects directly from the coefficients. Rather, our parameter estimates indicate whether a relationship is statistically significant and provides insight into the direction of these relationships based on sign. Thus positive (negative) coefficients indicate antecedents which increase (decrease) willingness to support the proposed policy (Table 4). The allocation of funds dependent variable is modeled with 11 bins from 0/100 (all funds allocated to renewable energy) to 100/0 where all funds are allocated to energy efficiency. Here positive (negative) coefficients indicate antecedents which increase (decrease) allocation to energy efficiency (Table 4).

\subsubsection{Preference for renewable energy types}

We note that individuals do have preferences for specific energy types, where individuals were more likely to support the policy relative to the land-based wind case if the policy scenario included either deepwater offshore wind or tidal energy. Interestingly, these are the two renewable energy types under development - but not yet available for residential use - in Maine. Consistent with our preliminary investigations we find no evidence of order effects in our data.

\subsubsection{Demographics}

We find no effect of age, income, household size, presence of children in the home or monthly electricity bill on either the willingness to support or the allocation decision. Of interest, we find 
that citizens who have lived longer in Maine are less likely to support the proposed program. Consistent with prior literature, we find that females are more likely to support the environmentally preferred choice by indicating higher willingness to support the proposed policy. Men in our study allocated more funds to energy efficiency than renewable energy, this is interesting in light of previous findings that females selected onshore wind over other renewable energy options (Kontogianni et al., 2013). Further, we find the expected negative impact of the program fee on willingness to support.

\subsubsection{Personal characteristics}

Individuals who perceive that climate change is happening, and has anthropogenic causes were, not surprisingly, more likely to support the policy, but these beliefs did not influence allocation of funds. Interestingly, the perception that renewable energy takes the focus off efficiency and the need to reduce consumptions did not impact the willingness to support, but exerts influence on the allocation decision in favor of energy efficiency investment. Individuals who report being more fiscally conservative were, unsurprisingly, less likely to indicate a willingness to support the proposed policy. However, it was a participant's socially conservative leanings that led to fewer dollars allocated to energy efficiency in the allocation decision. This may be due to the fact that residential energy efficiency programs are often geared toward lower-income households and may therefore not be perceived to be distributed equally. In contrast, investments in renewable energy supply would presumably be available across the citizenry. We note that prevention focused individuals are less likely to indicate a willingness to support the proposed policy. While previous studies have found that prevention focused individuals often comply with suggested green behavior (Miniero et al., 2014) the lack of support for the proposed new policy is consistent with status quo or stability, traits also associated with prevention focused individuals. In the allocation decision, promotion focused individuals allocated fewer funds to energy efficiency than renewable energy. Renewable energy may be viewed as more 
'progressive' and therefore more consistent with the traits associated with promotion individuals such as growth.

In sum, we have noted interesting results for each of our main hypothesis. We find that citizens have preferences for specific types of renewable energy, however these preferences do not yield significantly different allocation of energy investment funds between renewable energy and energy efficiency (H1). We find only limited evidence of order effects. Interestingly, we note that citizens do have demand for energy efficiency investments which warrants further investigation. Importantly, our results indicate that an individuals' personal characteristics, including their promotion/prevention focus, fiscal/social leanings and perceptions of climate change as well as relationships between renewable energy and energy efficiency influence both their willingness to support energy policies, but also their allocation of fund choices. Importantly, these metrics influence these two related, but distinct, decisions in different ways $(\mathrm{H} 2)$.

\section{Conclusions and policy implications}

Redesigning energy portfolios to reduce dependence on fossil fuels is a daunting feat, one which requires deep understanding of the complexities of individual decisions that directly impact public choices. Decision makers must build policy that is supported, or at least accepted, by the public. To that end, the key question of "what mix of options do citizens prefer in their energy portfolio' must be addressed and is best understood from surveys focused on citizens making the tradeoffs inherent in policy designed in a world with limited public financial resources. Consistent with Greenberg (2009) call for citizen energy-focused surveys directed at multiple sources our work is able to provide three key implications for design and implementation of policy and future research. 
First, our findings suggest that policy makers must move discussions of renewable energy and energy efficiency from the abstract to the concrete. Consistent with previous literature, we find citizens had energy-type specific preferences that were relevant in their support (or not) for our policy scenario. Citizens asked to support deepwater offshore wind, and tidal energy were more likely to support public investments in comparison to those who evaluated landbased wind. Public energy policy that does not differentiate the type of renewable energy options available for investment may face rejection by citizens who hold energy-type preferences. Moreover, it becomes important to identify the services (and savings) that may stem from energy efficiency investments. A heated debate over funding for Efficiency Maine occurred in spring 2015, where almost $\$ 38$ million in cuts occurred in March, and was not rectified until June by legislative override of a gubernatorial veto (Maine Legislature (127th), 2015). Awareness of citizen preferences may alleviate future issues surrounding allocation of funds ${ }^{4}$.

Second, our work indicates that policy makers need to provide opportunities for citizens to make allocation decisions regarding energy investments and not just be asked to support (or not) a predesigned policy. Our results suggest that support for policy, and subsequent allocation of funds, are related but distinct decisions. We see that different factors impacted these two decisions in our analysis. We find that when forced to allocate limited resources between energy efficiency or renewable energy investments, citizens allocate slightly more funding to energy efficiency. Importantly, our findings indicate that many citizens view renewable energy and energy efficiency as complementary efforts, not mutually exclusive. Current discussions of energy portfolios often inadvertently pit these two options against one another in the struggle for public funding. We find that policy makers should carefully consider policies which incorporate both options, consistent with citizens' preferences.

Third, consistent with work by Sovacool and Brown (2015) our results indicate that there is 'no such thing as a single, overarching perspective when it comes to ... contemporary energy 
problems' (p. 41). Energy options will be evaluated very differently by different individuals, where our work notes the importance of regulatory focus and political leanings in energy assessment. Improved understanding that energy efficiency may be viewed as preventative (and therefore attractive to prevention oriented individuals), and renewable energy as potential advancement (and attractive to promotion oriented individuals) will help energy policy makers communicate options to various constituencies. These lessons can also be applied in communications based on political leanings as well; it is crucial to our energy future that energy mixes attractive to multiple audiences be included in energy portfolios.

We are encouraged by the calls for interdisciplinary work in the energy realm including Stern (2014) urging that 'a more interdisciplinary approach will advance our understanding of energy issues' (p. 33) and Swim et al. (2011) indication that 'by attending to a variety of individual predictors, researchers can help explain instances in which individual and household behavior does not follow models of economic benefit maximization' (p. 243). We heed these calls by developing an experiment that uncovered resource allocation preferences in the energy realm, and investigated hitherto unexamined factors which may influence energy decisions. We urge future researchers to consider the important contributions of interdisciplinary work and social dimensions in understanding energy choices.

Footnotes:

${ }^{1}$ for information on the development of offshore wind energy in Maine visit www.DeepCwind.org; for information on tidal energy development in Maine visit http://orpc.co/.

${ }^{2}$ We examined our data for patterns in missed question responses. The willingness to support policy question was answered by 397 participants, however, many did not answer the complete set of covariates included in our model. We sample mean corrected demographic 
variables (income, education). We did not correct psychological metrics as we do not have information about their distribution across populations which would guide such corrections.

${ }^{3}$ We alter the dummy variables used in the allocation of funds decision by: (1) including an order effect variable (1 if energy efficiency was viewed in the first column; 0 if renewable energy was viewed); (2) including an interaction term that captures both type of energy and position of the renewable energy in the allocation scenario.

${ }^{4}$ The authors of this study released preliminary results of this study during this debate. Interview with the first author can be found at: http://news.mpbn.net/post/university-studysuggests-support-energy-efficiency. It should be noted that the cuts, and veto, appeared to be driven by politics rather than a lack of understanding of the programs capacity and outputs.

Acknowledgments

This research was conducted as part of Maine's Sustainability Solutions Initiative, supported by National Science Foundation (United States), award EPS-0904155 to Maine EPSCoR at the University of Maine. We thank two anonymous reviewers for comments that strengthened this manuscript. We also thank participants in the 2015 Maine Economics Conference who provided insightful comments on a presentation of this work.

References

Aaker, J.L., Lee, A.Y., 2001. 'I' seek pleasures and 'we' avoid pains: the role of self- regulatory goals in information processing and persuasion. J. Consum. Res. 28, 33-49.

Ajzen, I., 1991. The theory of planned behavior. Organ. Behav. Hum. Decis. Process. 50 (2), $179-211$. 
Bamberg, S., 2003. How does environmental concern influence specific environmentally related behaviors? A new answer to an old question. J. Environ. Psychol. 23, 21-32.

Balderjahn, I., 1988. Personality variables and environmental attitudes as predictors of ecologically responsible consumption patterns. J. Bus. Res. 17 (1), 51-56.

BP, 2013. BP Energy Outlook, 2030.

Boldero, J.M., Higgins, E.T., 2011. Regulatory focus and political decision making: when people favor reform over the status quo. Political Psychol. 32 (3), 399-418.

Borchers, A.M., Duke, J.M., Parsons, G.R., 2007. Does willingness to pay for green energy differ by source? Energy Policy 35 (6), 3327-3334.

Cicia, G., Cembalo, L., Giudice, T. Del, Palladino, A., 2012. Fossil energy versus nuclear, wind, solar and agricultural biomass: insights from an Italian national survey. Energy Policy 42, 59-66.

Crowe, E., Higgins, E.T., 1997. Regulatory focus and strategic inclinations: promotion and prevention in decision-making. Organ. Behav. Hum. Decis. Process. 69 (2), 117-132.

Database of State Incentives for Renewables and Efficiency (DSIRE), 2014. US Dept. of Energy. State profile: Maine. Available at: http://www.dsireusa.org/incentives/incentive.cfm?Incentive_Code ME01R (accessed 31.12.14).

Dietz, T., Stern, P.C., Weber, E.U., 2013. Reducing carbon-based energy consumption through changes in household behavior. Daedalus 142 (1), 78-89.

Dillman, D., Smyth, J., Christian, J., 2009. Internet, Mail, and Mixed-Mode Surveys: the Tailored Design Methods, 3rd edition. John Wiley and Sons, Inc., New Jersey.

Dunlap, R.E., McCright, A.M., 2008. A widening gap: Republican and Democratic views on climate change. Environ.: Sci. Policy Sustain. Dev. 50 (5), 26-35.

Ek, K., 2005. Public and private attitudes towards 'green' electricity: the case of Swedish wind power. Energy Policy 33 (13), 1677-1689.

Energy Information Administration (EIA), 2014. State Profile and Energy Estimates: Maine. 
Available at: http://www.eia.gov/state/?sid=ME (accessed 31.12.14).

Ertör-Akyazı, P., Adaman, F., Özkaynak, B., Zenginobuz, Ü., 2012. Citizens' preferences on nuclear and renewable energy sources: evidence from Turkey. Energy Policy 47, 309-320.

Farhar, B.C., 1994. Trends in US public perceptions and preferences on energy and environmental policy. Annu. Rev. Energy Environ. 19 (1), 211-239.

Förster, J., 2003. The influence of approach and avoidance motor actions on food intake. Eur. J. Soc. Psychol. 33 (3), 339-350.

Gerpott, T.J., Mahmudova, I., 2010. Determinants of green electricity adoption among residential customers in Germany. Int. J.Consum. Stud. 34 (4), 464-473.

Greenberg, M., 2009. Energy sources, public policy, and public preferences: analysis of US national and site-specific data. Energy Policy 37 (8), 3242-3249.

Grösche, P., Schröder, C., 2011. Eliciting public support for greening the electricity mix using random parameter techniques. Energy Econ. 33 (2), 363-370.

Hartmann, P., Ibáñez, V. Apaolaza, Sainz, F.J. Forcada, 2005. Green branding effects on attitude: functional versus emotional positioning strategies. Mark. Intell. Plan. 23 (1), 9-29.

Hansla, A., Gamble, A., Juliusson, A., Gärling, T., 2008. Psychological determinants of attitude towards and willingness to pay for green electricity. Energy Policy 36 (2), 768-774.

Hansla, A., 2011. Value orientation and framing as determinants of stated willingness to pay for eco-labeled electricity. Energy Effic. 4 (2), 185-192.

Hernandez, B., Tabernero, C., Suarez, E., 2010. Psychosocial motivations and self-regulation processes that activate environmentally responsible behavior (Chapter 5). In: Valentin, Jorge, Gamez, Lucila (Eds.), Environmental Psychology: New Developments. Nova Science Publishers Inc.

Higgins, E.T., 2000. Making a good decision: value from fit. Am. Psychol. 55, 1217-1230. Higgins, E.T., 2002. How self-regulation creates distinct values: the case of promotion and prevention decision making. J. Consum. Psychol. 12, 177-191.

Jost, J.T., Glaser, J., Kruglanski, A.W., Sulloway, F.J., 2003. Political conservatism as motivated 
social cognition. Psychol. Bull. 129 (3), 339.

Kirmani, A., Zhu, R., 2007. Vigilant against manipulation: the effect of regulatory focus on the use of persuasion knowledge. J. Mark. Res. 44 (4), 688-701.

Kontogianni, A., Tourkolias, C., Skourtos, M., 2013. Renewables portfolio, individual preferences and social values towards RES technologies. Energy Policy 55, 467-476.

Landsberg, H.H., 1974. Low-cost, abundant energy: paradise lost? Science 184 (4134), 247-254.

Lawrence Livermore National Laboratory, 2014. Estimated US Energy Use in 2013. https://flowcharts.1lnl.gov/ (accessed 29.04.14).

Liberman, N., Idson, L.C., Camacho, C.J., Higgins, E.T., 1999. Promotion and prevention choices between stability and change. J. Personal. Soc. Psychol. 77, 1135-1145.

Lucas, G.M., Molden, D.C., 2011. Motivating political preferences: concerns with promotion and prevention as predictors of public policy attitudes. Motiv. Emot. 35 (2), 151-164.

Maine Legislature (127th), 2015. Legislative Directive 1215, 'An Act to Provide Lower Energy Costs to Maine Businesses and Residences by Carrying Out the Legislature's Intent Regarding Funding of the Efficiency Maine Trust. Available at: www.mainelegislature.org.

Manley, D.K., Hines, V.A., Jordan, M.W., Stoltz, R.E., 2013. A survey of energy policy priorities in the United States: energy supply security, economics, and the environment. Energy Policy 60, 687-696.

McGregor, I., Zanna, M.P., Holmes, J.G., Spencer, S.J., 2001. Compensatory conviction in the face of personal uncertainty: going to extremes and being oneself. J. Personal. Soc. Psychol. $80(3), 472$.

Menegaki, A., 2008. Valuation for renewable energy: a comparative review. Renew. Sustain. Energy Rev. 12 (9), 2422-2437.

Miniero, G., Codini, A., Bonera, M., Corvi, E., Bertoli, G., 2014. Being green: from attitude to actual consumption. Int. J. Consum. Stud. 38 (5), 521-528.

Painuly, J.P., 2001. Barriers to renewable energy penetration; a framework for analysis. Renew. Energy 24 (1), 73-89. 
Pew Research Center for the People \& the Press, 2010. Fueling Both Sides of the Energy Debate. http://pewresearch.org/pubs/1627/inconsistent-American-views-energy-environment-firstlady-still-popular-obama-and-palin-less-so (accessed 24.04.2015).

Pham, M.T., Chang, H.H., 2010. Regulatory focus, regulatory fit, and the search and consideration of choice alternatives. J. Consum. Res. 37, 626-640.

Ribeiro, F., Ferreira, P., Araújo, M., Braga, A.C., 2014. Public opinion on renewable energy technologies in Portugal. Energy 69, 39-50.

Roberts, J.A., Bacon, D.R., 1997. Exploring the subtle relationships between environmental concern and ecologically conscious consumer behavior. J. Bus. Res. 40 (1), 79-89.

Roe, B., Teisl, M.F., Levy, A., Russell, M., 2001. US consumers' willingness to pay for green electricity. Energy Policy 29 (11), 917-925.

Samuelson, W., Zeckhauser, R., 1988. Status quo bias in decision making. J. Risk Uncertain. 1 (1), 7-59.

Sardianou, E., Genoudi, P., 2013. Which factors affect the willingness of consumers to adopt renewable energies? Renew. Energy 57, 1-4.

Sapci, O., Considine, T., 2014. The link between environmental attitudes and energy consumption behavior. J. Behav. Exp. Econ. 52, 29-34.

Scarpa, R., Willis, K., 2010. Willingness-to-pay for renewable energy: primary and discretionary choice of British households' for micro-generation technologies. Energy Econ. 32 (1), 129136.

Sovacool, B.K., Brown, M.A., 2015. Deconstruction facts and frames in energy research: maxims for evaluating contentious problems. Energy Policy 86, 36-42.

Sovacool, B.K., 2014. Diversity: energy studies need social science. Nature 511, 529-530. Sovacool, B.K., Ryan, S.E., Stern, P.C., Janda, K., Rochlin, G., Spreng, D., Lutzenhiser, L., 2015. Integrating social science in energy research. Energy Res. Soc. Sci. 6, 95-99. StataCorp, 2015. Stata Statistical Software: Release 14. StataCorp LP, College Station, TX. Stern, P.C., 1992. What psychology knows about energy conservation. Am. Psychol. 47 (10), 
Stern, P.C., 2011. Contributions of psychology to limiting climate change. Am. Psychol. 66 (4), 303.

Stern, P.C., 2014. Energy: we need all hands on deck. Nature 513 (7516), 33.

Smil, V., 2003. Energy at the Crossroads: Global Perspectives and Uncertainties. MIT press, USA.

Spence, A., Poortinga, W., Pidgeon, N., Lorenzoni, I., 2010. Public perceptions of energy choices: the influence of beliefs about climate change and the environment. Energy Environ. $21(5), 385-407$.

Swim, J.K., Stern, P.C., Doherty, T.J., Clayton, S., Reser, J.P., Weber, E.U., Howard, G.S., 2011. Psychology's contributions to understanding and addressing global climate change. Am. Psychol. 66 (4), 241.

Tabi, A., Hille, S.L., Wüstenhagen, R., 2014. What makes people seal the green power deal? Customer segmentation based on choice experiment in Germany. Ecol. Econ. 107, 206-215.

Teisl, M., Roe, B., Vayda, M., 2006. Incentive effects on response rates, data quality, and survey administration costs. Int. J. Public Opin. Res. 18 (3), 364-373.

United States Census Bureau, 2013. State \& Country Quick Factsl Maine. Available at: http://quickfacts.census.gov/qfd/states/23000.html (accessed 13.08.15).

von Borgstede, C., Andersson, M., Johnsson, F., 2013. Public attitudes to climate change and carbon mitigation - implications for energy-associated behaviours. Energy Policy 57, $182-$ 193.

Wang, J., Lee, A.Y., 2006. The role of regulatory focus in preference construction. J. Mark. Res. $43(1), 28-38$.

Werth, L., Förster, J., 2007. How regulatory focus influences consumer behavior. Eur. J. Soc. Psychol. 37 (1), 33-51.

Zarnikau, J., 2003. Consumer demand for 'green power' and energy efficiency. Energy Policy 31 (15), 1661-1672. 
Figures

Table 1

Demographic profile of respondents $(N=397)$ and 2013 US census data for Maine.

\begin{tabular}{lll}
\hline & Respondents & Census \\
\hline Gender (\% male) & $63 \%$ & $49 \%$ \\
Age (mean; years) & 57.3 & $43.5^{\mathrm{a}}$ \\
Income (median annual household; \$) & 71,153 & $48,453^{\mathrm{b}}$ \\
Education (years) & 14.8 & 14.0 \\
Children in household (\% with children in & $21 \%$ & $19 \%$ \\
$\quad$ & 41.2 & Not available \\
$\quad$ household) & 2.3 & 2.3 \\
Hours of Maine Residency & 100.2 & Not available \\
Monthly electric bill (self-reported) &
\end{tabular}

a Median age for Maine 2012. (United States Census Bureau (2013))

b Median in Maine for 2009-2013. 
Fig. 1. Sample energy policy scenario contained in survey (where renewable energy type shown is Hydroelectric, and order of options is energy efficiency in first column).

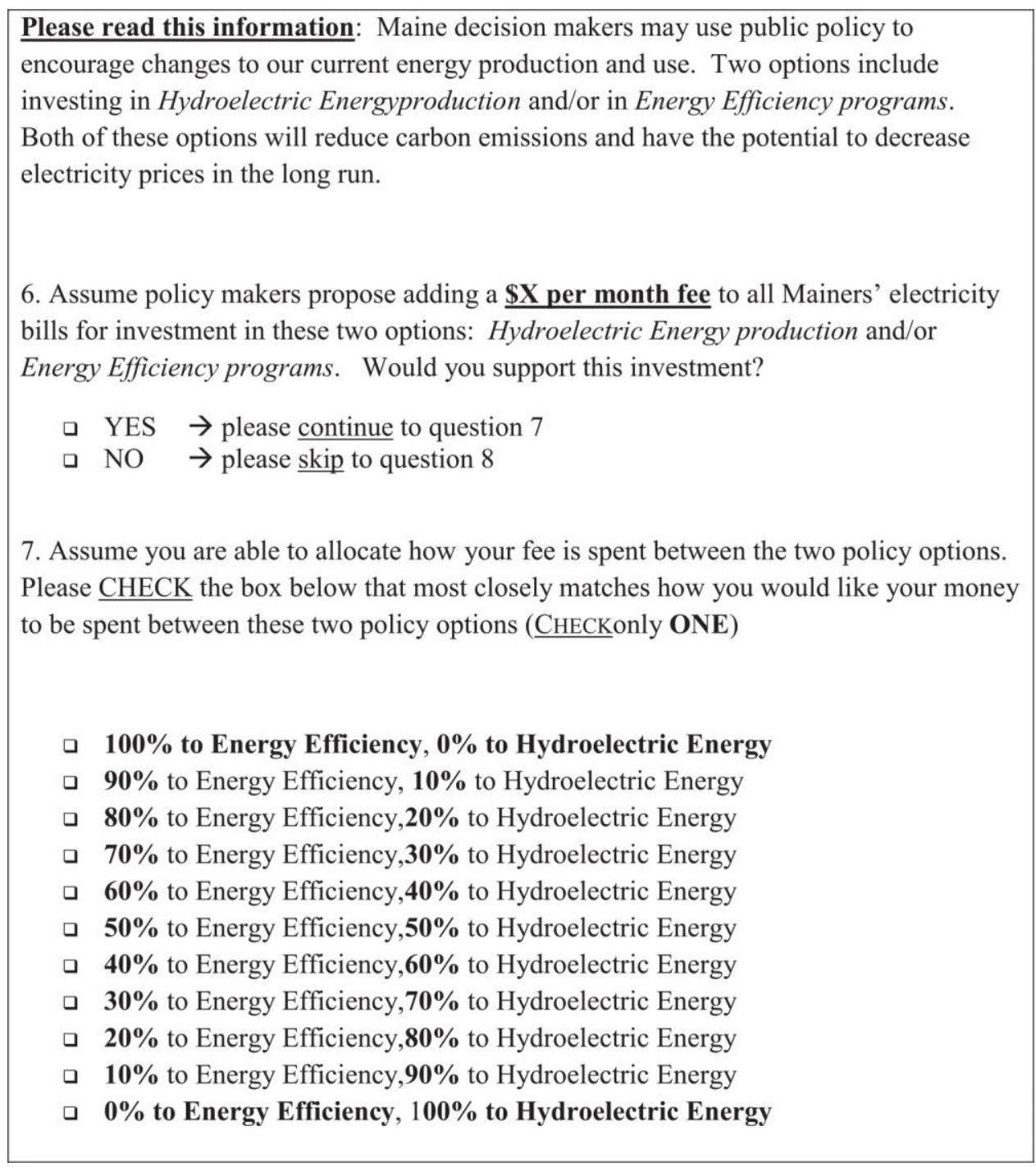


Table 2

Descriptive statistics of policy scenario.

$N$ Percent agreeing to support policy which Min. amount of fee of Mean amount of fee of Max amount of fee Mean percent of funds allocated included this supply type or efficiency (\%)

supporter

of support

to energy efficiency (\%)

\begin{tabular}{|c|c|c|c|c|c|c|}
\hline Land & 99 & 50.50 & $\$ 1$ & $\$ 5.18$ & $\$ 14$ & 59.4 \\
\hline Deep & 96 & 52.08 & $\$ 1$ & $\$ 6.38$ & $\$ 15$ & 53.1 \\
\hline Hydro & 102 & 48.04 & $\$ 1$ & $\$ 7.65$ & $\$ 15$ & 57.1 \\
\hline Tidal & 100 & 58.0 & $\$ 1$ & $\$ 7.69$ & $\$ 15$ & 53.8 \\
\hline Total/avg & 397 & 52.14 & $\$ 1$ & $\$ 6.76$ & $\$ 15$ & 55.8 \\
\hline
\end{tabular}


Fig. 2. Support for proposed energy policy scenario, by amount of fee (per month) and energy type evaluated.

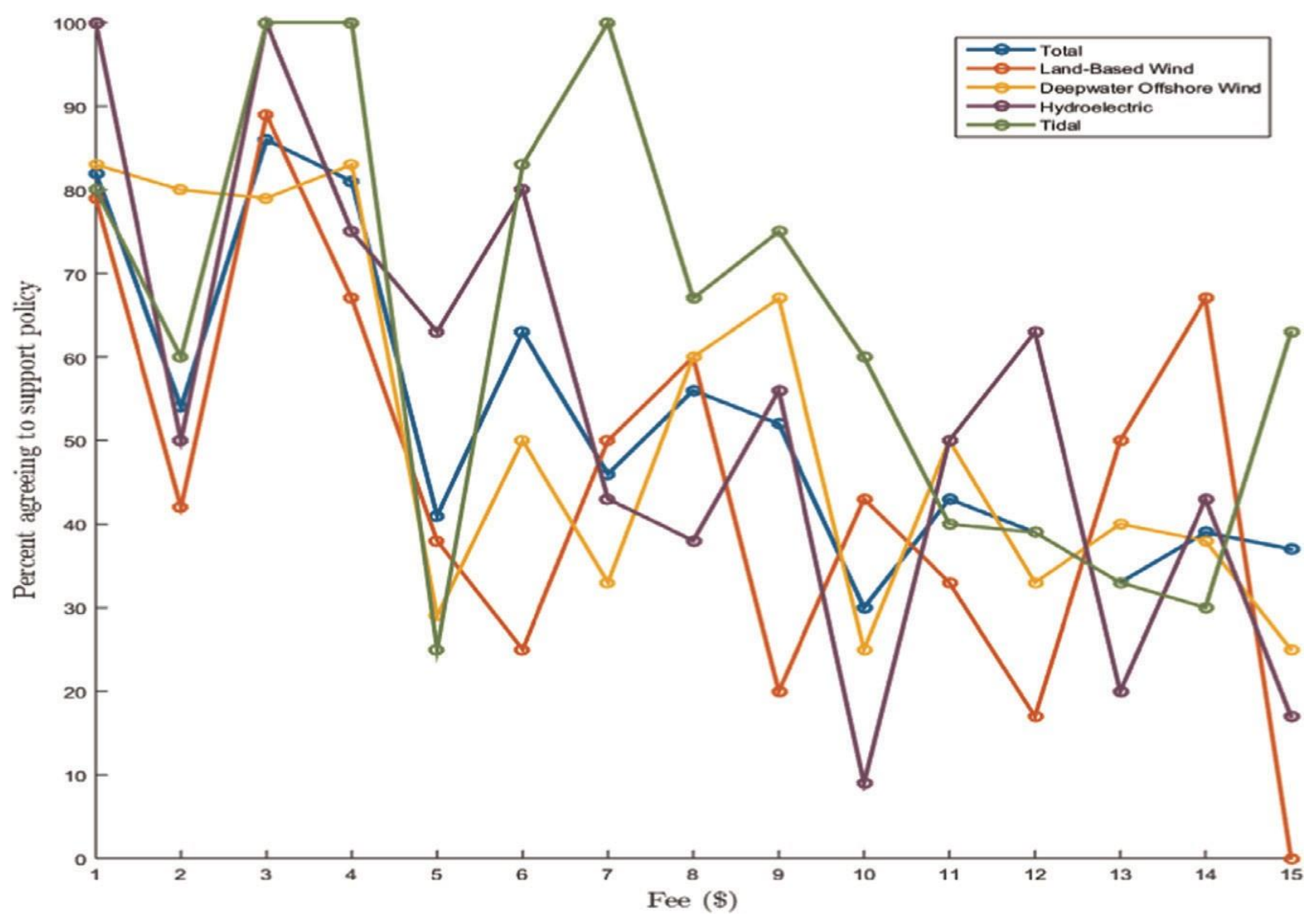


Table 3

Socio-demographic and personal profiles of policy supporters and non-supporters.

\begin{tabular}{|c|c|c|}
\hline & Supporters & Non-supporters \\
\hline \multicolumn{3}{|l|}{ Socio-demographics } \\
\hline Gender (\% male) $)^{*}$ & $63 \%$ & $68 \%$ \\
\hline Age (mean; years) ${ }^{* *}$ & 57.3 & 58.9 \\
\hline Income (median; \$) & 71,153 & 64,780 \\
\hline Education (years) ${ }^{*}$ & 14.8 & 14.5 \\
\hline $\begin{array}{l}\text { Children in household (\% with children in } \\
\text { household) }\end{array}$ & $21 \%$ & $18.0 \%$ \\
\hline Years of Maine Residency ${ }^{* *}$ & 41.2 & 45.4 \\
\hline Household size (\# of people) & 2.3 & 2.19 \\
\hline Monthly electric bill (self-reported) & 100.2 & 97.9 \\
\hline \multicolumn{3}{|l|}{ Personal variables } \\
\hline Social leanings** & 3.7 & 4.25 \\
\hline Fiscal leanings & 4.4 & 5.0 \\
\hline Climate change perceptions ${ }^{* *}$ & 10.4 & 9.4 \\
\hline Renewable energy taking focus off efficiency & 3.7 & 3.9 \\
\hline $\begin{array}{l}\text { Renewable energy taking focus off consump- } \\
\text { tion reduction }\end{array}$ & 3.6 & 3.9 \\
\hline Promotion focus & 5.2 & 5.0 \\
\hline Prevention focus * & 3.9 & 4.2 \\
\hline
\end{tabular}

Statistical difference between supporters and non-supporters at

* at $p=.10$.

$p=.05$. 


\section{Table 4}

Regression results, factors influencing respondent willingness to support energy policy $(1=$ Yes $)$ and allocation decision (100 is all funds to energy efficiency) $(N=304)$.

Willingness to sup- Allocation of funds port policy decision

\begin{tabular}{|c|c|c|}
\hline \multicolumn{3}{|l|}{ Controls } \\
\hline Amount of fee & $-.110^{* * *}$ & -.014 \\
\hline $\begin{array}{l}\text { Proposal included deepwater } \\
\text { offshore wind }\end{array}$ & $.424^{*}$ & \\
\hline $\begin{array}{l}\text { Proposal included hydroelectric } \\
\text { power }\end{array}$ & .242 & \\
\hline Proposal included Tidal Energy & $.520^{* *}$ & \\
\hline $\begin{array}{l}\text { Order effect }(1=\text { energy effi- } \\
\text { ciency in first column) }\end{array}$ & - & .578 \\
\hline $\begin{array}{l}\text { Deepwater offshore wind first } \\
\text { on allocation list }\end{array}$ & - & -.174 \\
\hline $\begin{array}{l}\text { Hydroelectric power first on al- } \\
\text { location list }\end{array}$ & - & -.316 \\
\hline $\begin{array}{l}\text { Tidal energy first on allocation } \\
\text { list }\end{array}$ & - & -.159 \\
\hline \multicolumn{3}{|l|}{ Demographics } \\
\hline Age (years) & .002 & .007 \\
\hline Income ( $\$ 10,000 ' s)$ & .0 .168 & -0.051 \\
\hline Gender $($ male $=1)$ & $-.323^{*}$ & $.387^{* *}$ \\
\hline Education (years) & -.026 & -.004 \\
\hline Years lived in Maine & $-.014^{* * *}$ & -.003 \\
\hline Number of persons in household & .108 & -.022 \\
\hline $\begin{array}{l}\text { Presence of children in house- } \\
\text { hold (Yes }=1 \text { ) }\end{array}$ & -.076 & .072 \\
\hline Monthly electric bill & -.0004 & .0007 \\
\hline \multicolumn{3}{|l|}{ Personal characteristics } \\
\hline Social leanings & -.024 & $-.237^{* * *}$ \\
\hline Fiscal leanings & $-.191^{* * * *}$ & .083 \\
\hline Climate change perceptions & $.046^{*}$ & -.004 \\
\hline $\begin{array}{l}\text { Renewable energy taking focus } \\
\text { off efficiency }\end{array}$ & -.076 & $.122^{*}$ \\
\hline $\begin{array}{l}\text { Renewable energy taking focus } \\
\text { off consumption reduction }\end{array}$ & .004 & $.108^{*}$ \\
\hline Promotion focus & .030 & $-.163^{*}$ \\
\hline Prevention focus & $-.158^{* *}$ & .083 \\
\hline
\end{tabular}

${ }^{*} p<.10$.

${ }^{* *} p<.05$.

${ }^{* * *} p<.01 ; \operatorname{LR}(41)=121.27, p>\chi^{2}=0$. 